\title{
A CONSTITUIÇÃO COMO ÁRVORE VIVA DE WIL WALUCHOW: POR UMA NOVA CONCEPÇÃO DE CORPO E DE SUAS RAÍZES
}

\section{THE CONSTITUTION AS A LIVING TREE OF WIL WALUCHOW: FOR A NEW DESIGN OF BODY AND THEIR ROOTS}

\section{Estefânia Maria de Queiroz Barboza ${ }^{1}$ \\ Bryan Bueno Lechenakoski²}

\begin{abstract}
RESUMO: A Revisão Judicial ou o Judicial Review guarda profundos desacordos na doutrina e jurisprudência, uma vez que questões em torno da legitimidade, caráter democrático, dentre outros aspectos acerca do Poder Judiciário poder rever ou declarar inconstitucional atos normativos emanados dos demais Poderes (Executivo e Legislativo) são objetos de debates intensos na doutrina, sendo questionado até mesmo se a própria Constituição ou Carta de Direitos é dotada de um caráter democrático ou não. Para o estudo de tal fenômeno,o presente artigo percorre primeiramente quais os caminhos que levaram o Poder Judiciário ser incumbido de tal poder, ou seja, avalia a virada que ocorreu do Estado Legal para o Estado Constitucional, com a possível abertura para a interpretação judicial nesta mudança de compreensão de todo sistema. Após, avalia a posição desfavorável e a posição favorável à Revisão Judicial, surgindo assim, a importância de se analisar uma terceira posição, a de Wil Waluchow e sua teoria da Constituição como Árvore Viva. A partir de toda a avaliação das posições favoráveis e desfavoráveis e esta terceira teoria, o artigo enfrenta se a Revisão Judicial é desejável ou não, e quais seriam seus limites, bem como se a teoria da Constituição como Árvore Viva seria desejável para o Brasil através de pequenas mudanças para sua aplicação no ordenamento jurídico brasileiro.
\end{abstract}

Palavras-Chave: Revisão judicial; Interpretação das leis; Democracia; Constituição como Árvore Viva.

\footnotetext{
${ }^{1}$ Doutora em Direito pela Pontifícia Universidade Católica do Paraná (PUCPR) com estágio Doutoral na Osgoode Hall Law School, Toronto, Canadá. Menção Honrosa no Prêmio Capes de Tese de 2012. Professora de Direito Constitucional dos Programas de Graduação e Pós-Graduação da Universidade Federal do Paraná (UFPR) e do Mestrado em Direito da UNINTER. Pesquisadora do Centro de Estudos da Constituição (CCONS). E-mail: estefaniaqueiroz@uol.com.br. ORCID: http://orcid.org/0000-00029829-5366.

${ }^{2}$ Mestrando em Direito, bolsista 100\% no Centro Universitário Internacional - UNINTER, orientador Rui Carlo Dissenha. Pós-graduado em Direito Penal e Processo Penal na Academia Brasileira de Direito Constitucional. Pós-graduado em Direito Contemporâneo no Curso Jurídico. Formado em Direito pela Universidade Positivo. Advogado. E-mail: lechenakoski.adv@gmail.com. ORCID: https://orcid.org/0000-0002-1546-6984.
} 
ABSTRACT: The concern with the interpretation made by the judges is recurrent in the academic community, and its legitimacy, the democratic aspect, as well as its limits for such action are often cited by the doctrine, both those who adopt a favorable position and those who adopt a position unfavorable. Such concerns and criticisms do not refer only to judicial review itself, but also address the notion of a Constitution or Charter of Rights as a fixed and pre-established point. Thus, this article seeks to mention what we believe to be the main criticisms and favorable arguments for having a Constitution with fundamental rights, as well as for the judicial review itself, to verify if it is permissible to adopt a hierarchically superior Constitution the laws promulgated by the Legislative Power and by the Executive Branch, as well as with regard to the judicial review system in Brazil, or even if the Constitution and judicial review are desirable, and, if so, what their limits would be, bringing as a possibility the notion of Constitution as a tree Wil Waluchow, suggesting small changes in theory.

Keywords: Judicial Review; Interpretation of laws; Democracy; Constitution as a Living Tree.

Sumário: 1. Introdução. 2. A tomada de decisão por parte do poder judiciário. 2.1. Revisão judicial e a interferência do poder judiciário nos demais poderes - problemas de legitimidade e democracia?; 2.1.1 o que é e quais as raízes do sistema de revisão judicial; 2.1.2. Críticas à revisão judicial; 2.1.3. Argumentos favoráveis à revisão judicial e ao constitucionalismo democrático; 3. Uma nova compreensão de constituição? A Constituição como árvore viva de Wil Waluchow; 4. As raízes da árvore como sendo os Direitos Humanos e a Constituição da República; 5. Apontamentos Finais. 6. Referências.

\section{INTRODUÇÃO}

Com a virada do Estado Legal para o Estado Constitucional, houve uma mudança paradigmática na forma como se compreende o direito e na aplicação das normas, passando a Constituição a ser considerada como norma hierarquicamente superior a todas as outras normas infraconstitucionais. Ainda, abriram-se as portas para que o Poder Judiciário entrasse em cena e pudesse interpretar as leis e atos do Poder Legislativo e do Poder Executivo, bem como declará-las constitucionais ou inconstitucionais de acordo com a lei suprema. Além da quebra desse paradigma, houve o fenômeno da globalização, abrindo-se espaço para os direitos internacionais, em 
especial a preocupação com a proteção e promoção de Direitos Humanos nos Estados soberanos.

Desta forma, para a compreensão do que irá ser proposto é inevitável e desejável a análise de tais fenômenos como primado do presente trabalho.

Em conjunto a essas mudanças, a discussão acerca da tomada de decisão pelo Poder Judiciário e o poder de rever os atos das instituições tidas como democráticas cresceu, sendo que diversos autores de todo o mundo se preocupam com a temática, ou seja, se o Poder Judiciário pode rever os atos dos demais poderes, e assim, em um segundo momento, a análise se concentrará em analisar os argumentos favoráveis e os argumentos desfavoráveis com relação a Revisão Judicial, devendo também ser estudado o caráter democrático ou não de uma Constituição ou Carta de Direitos.

Após, enfrenta-se, ainda, a dúvida acerca dos limites de atuação do Poder Judiciário, uma vez que concentrar tanto poder nas mãos de um dos órgãos estatais, poderia acarretar prejuízos imensuráveis à própria noção de democracia, bem como aos direitos e garantias conquistados ao longo da história, e, para tal discussão é trazida à baila a teoria de Wil Waluchow sobre a Constituição como Árvore Viva, enfrentando o debate acerca da possibilidade da Revisão Judicial, do caráter democrático da Constituição, e como adequar o Direito ao avanço da sociedade, de modo a atender os anseios das novas gerações.

Como a teoria de Wil Waluchow é elaborada para o sistema do Common Law, há necessidade de analisar a possibilidade de se adequar a teoria para o sistema judicial do Brasil, ou seja adequar a teoria da Árvore Viva de Wil Waluchow ao Civil Law, e, consequentemente, se seria desejável a sua aplicação no Brasil como forma de limites na tomada de decisão quando exercida a Revisão Judicial pelos juízes.

\section{A TOMADA DE DECISÃO POR PARTE DO PODER JUDICIÁRIO}


Há grande preocupação na tomada de decisão pelo Poder Judiciário, sendo que a interferência do Poder Judiciário nos Poderes Legislativo e Executivo gera uma grande crise na teoria da separação de poderes. A problemática se torna ainda mais contundente quando o Poder Judiciário ingressa nas competências do Poder Legislativo, bem como cassa leis promulgadas por estes declarando sua inconstitucionalidade, porém este fenômeno da revisão judicial está interligado com a própria noção de Estado Constitucional de Direito, bem como da noção de superioridade das Constituições, e é justamente o que se procurará evidenciar neste capítulo.

2.1 a revisão judicial e a interferência do poder judiciário nos demais poderes Problemas de legitimidade e democracia?

\subsubsection{As raízes do sistema de revisão judicial}

Não é de hoje a polêmica que circunda as decisões judiciais que interferem em leis promulgadas pelo Poder Legislativo e Executivo, atento que a história não é linear, bem como momentos históricos podem não estar ligados diretamente como se fossem uma continuação, para estabelecer uma lógica argumentativa, basta para o que se pretende, apontar alguns momentos cruciais acerca da revisão judicial promovida pelo Poder Judiciário, que como visto, decorre do próprio Estado Constitucional de Direito.

De acordo com Vanberg (2004, p. I), a revisão judicial pode ser definida como "[...] o poder dos órgãos judiciais de anular os atos legislativos ou administrativos ordinários, se os juízes concluírem que eles estão em conflito com a constituição".

No campo da política, Hirschl (2009, p. 140) menciona que "a judicialização da política agora inclui a transferência massiva, para os tribunais, de algumas das mais centrais e polêmicas controvérsias políticas em que uma democracia pode se envolver".

Há alguns autores, como Waldron (2006, p. 1354), que classificam e subdividem a revisão judicial como forte ou fraca, sendo que para o autor em uma revisão judicial 
forte "os tribunais têm a autoridade para recusar a aplicar um estatuto em um caso particular (...) ou modificar o efeito do estatuto para fazer com que sua aplicação esteja em conformidade com os direitos individuais" (WALDRON, 2006, p. 1354), e por outro lado, na revisão judicial fraca "os tribunais podem examinar a legislação para a sua conformidade com os direitos individuais, mas eles não podem recusar-se a aplicá-la" (WALDRON, 2006, p. 1355), sendo que em obra mais recente, Waldron (2018, p. 6263), volta a reafirmar os dois modelos de revisão judicial, esclarecendo que sua crítica reside na revisão judicial forte conforme será visto.

É importante destacar que Waldron (2018) trabalha a revisão judicial como um controle do judiciário sobre as leis promulgadas pelo legislativo, abstendo-se do controle judicial sobre o Poder Executivo, mencionando que com relação ao Poder Executivo é "quase universalmente aceito que as credenciais do executivo estão submetidas ao princípio básico do Estado de Direito (regra da lei) e, como resultado, que os tribunais podem requerer que os funcionários atuem conforme seus poderes legais" (WALDRON, 2018, p. 61).

A revisão judicial, para os autores que a defendem, pode ser encarada como uma poderosa arma em "que a democracia deve proteger-se contra a tirania do governo da maioria através da constitucionalização e da revisão judicial" (HIRSCHL, 2004, p. 72).

$\mathrm{O}$ aparecimento do constitucionalismo moderno decorreu principalmente após os períodos conturbados marcado pelo autoritarismo, sendo que Hirschl (2004, p. 139) menciona que os países "pós-autoritários no antigo Bloco Oriental, no sul da Europa, na América Latina e na Ásia rapidamente adotaram princípios do constitucionalismo moderno durante suas transições para a democracia".

Contudo, conforme já alertado, é impossível definir o fenômeno do constitucionalismo ou revisão judicial com começo, meio e fim, vez que o poder de rever os atos do legislativo e executivo estavam previstos até mesmo antes das Constituições rígidas, bem como das Constituições europeias, sendo que nos EUA já havia o exemplo acerca da análise do constitucionalismo das leis, e Ferrajoli (2006, p. 
432) neste contexto menciona que foi "a partir do célebre julgamento Malbury versus Madison de 1803 sobre uma lei em contraste com ela [...]" que a revisão judicial ganhou força nos EUA.

Em que pese não podermos fixar quando começou a revisão judicial, tem-se que o caso Malbury vs. Madison é um grande marco histórico para o sistema de controle de constitucionalidade, uma vez que de acordo com Vanberg (2004, p. 9) a partir de tal decisão nos EUA se "estabeleceu um precedente para a invalidação de um estatuto federal por razões constitucionais".

Cabe frisar que nenhuma das constituições europeias, em que pese serem formalmente rígidas, previam um sistema de revisão judicial das leis, a não ser a Constituição Austríaca de 1920 que foi "redigida pelo conhecido estudioso jurídico Hans Kelsen" (VANBERG, 2004, p. 9), e neste contexto foi "que a revisão constitucional finalmente ganhou uma posição segura no continente europeu" (VANBERG, 2004, p. 9), que previa "uma especial jurisdição sobre a constitucionalidade das leis" (FERRAJOLI, 2006, p. 433).

Entretanto, há uma diferença fundamental entre o modelo austríaco e o modelo americano acerca da possibilidade da revisão judicial dos atos do Legislativo e do Executivo, sendo que na Europa o modelo seguido buscava concentrar "o poder de revisão em um tribunal constitucional que atuasse fora da hierarquia judicial ordinária e tivesse jurisdição exclusiva sobre questões constitucionais" (VANBERG, 2004, p. 10), e por outro lado, o modelo dos EUA estabelecia um sistema descentralizado em que qualquer tribunal pudesse exercer o controle de constitucionalidade (VANBERG, 2004, p. 10).

No Brasil, a revisão judicial ganhou notoriedade e apoio doutrinário à partir da promulgação da Constituição de 1988, a qual "passou a ser compreendida não mais como documento meramente definidor da organização do Estado e da repartição de competências" (GODOY, 2017, p. 46), mas abrangendo um rol maior de atribuições 
"como projeto de construção nacional, definindo os princípios e objetivos da República, estabelecendo os direitos e garantias fundamentais [...]" (GODOY, 2017, p. 46).

Sendo assim a Constituição de 1988 promove uma reviravolta no sistema brasileiro, deixando de ser apenas uma Constituição cujo objetivo era definir a separação de poderes e organização de Estado, para ser uma Constituição que determinasse o cumprimento de determinadas garantias fundamentais aos cidadãos.

Assim, a Constituição brasileira passa a ser encarada como mecanismo de promoção de direitos, abrindo espaço também para a interpretação das leis em face da Constituição, ingressando neste momento a figura do intérprete constitucional, pois tendo em vista o caráter abstrato de suas normas, especialmente daquelas que tratam de direitos fundamentais, há necessidade da concretização através da densificação das mesmas, o que, por sua vez, se faz por meio do trabalho interpretativo.

Contudo, em que pese a revisão judicial parecer algo decorrente e normal do fenômeno do constitucionalismo contemporâneo, tal modalidade de rever os atos dos demais poderes, bem como o poder concentrado nas mãos do Poder Judiciário, guarda severas críticas na doutrina conforme se verá a seguir.

\subsubsection{Críticas à revisão judicial}

Talvez uma das principais críticas ao judicial review reside na ausência de legitimidade democrática do Poder Judiciário em rever os atos e decisões dos demais poderes, bem como o poder de anular algum ato que foi proferido por um Poder teoricamente democrático.

Neste passo, Barboza (2007) cita que um dos argumentos que são contrários à interpretação constitucional das normas em face da Constituição nos EUA segue no sentido de que a interpretação realizada pelo Poder Judiciário seria antidemocrática, uma vez que realizada "por um grupo de juízes não-eleitos e irresponsáveis perante os eleitores" (BARBOZA, 2007, p. 26). 
Neste contexto, Gargarella (1997) menciona que os defensores da revisão judicial fundamentam suas posições mencionando que os juízes não estão adstritos às pressões populares majoritárias que vão contra as minorias, e por tal motivo estariam mais aptos a tomar decisões nos casos levados a sua apreciação, ou até mesmo que estejam mais próximos dos problemas que afetam o povo. (GARGARELLA, 1997, p. 57).

Contudo, Gargarella (1997) adverte que não há como se afirmar que o Judiciário será imparcial, e que cumprirá bem a função de defender as minorias e aplicar decisões contramajoritárias de modo a proteger direitos fundamentais. Ao contrário, juízes podem compreender equivocadamente os pontos de vista deste grupo a ser atendido, bem como carecem de uma motivação para representar devidamente os interesses daqueles que supostamente queiram representar. (GARGARELLA, 1997, p. 57).

No mesmo sentido, em que pese o juiz possuir o dever de fundamentar suas decisões e não poder pautar em concepções filosóficas ou religiosas, Gargarella (1997, p. 68) segue na crítica de que alguns julgadores "tendem a confiar em concepções mais ou menos amplas do bem, ou a ocultar sua invocação de valores particulares em uma linguagem supostamente neutra".

Waldron (2006, p. 1363) acerca dos problemas de legitimidade, esclarece que "os tribunais em sua maioria não são instituições eletivas ou representativas, (...)mas também que o Judiciário não é permeado por um costume de eleições, representação e prestação de contas eleitorais da mesma forma que o Legislativo".

Continuando, Waldron (2006) ainda esclarece que, em que pese as eleições do Poder Legislativo possuírem defeitos e críticas, tal processo ainda é preferível em relação ao judicial review, pois seria superior em questões de democracia e valores democráticos, já que para ele os juízes não possuem credenciais eleitorais e nem responsabilidade perante os eleitores (WALDRON, 2006, p. 1391).

Gargarella (1997, p. 57) menciona que alguns juízes e juristas invocam em suas fundamentações o pretexto da vontade popular, sem possivelmente conhecerem tal vontade, bem como não estarem agindo de acordo com a vontade do povo, o que 
descontrói a argumentação de que os juízes conseguiriam defender interesses de minorias.

Ademais, aos que se posicionam de modo desfavorável a Constituição como documento democrático e contra a revisão judicial, argumentam no sentido de que o Poder Judiciário ao interpretar as normas constitucionais, muitas vezes não as interpreta em seu sentido literal, ou seja, de acordo com a própria vontade do constituinte. Ainda, argumentam que em casos em que há uma lacuna na Constituição, os juízes são chamados a resolver controvérsias legislativas complexas, o que acabaria por interferir diretamente nas competências do Poder Legislativo ou do Executivo quando ultrapassa as barreiras da própria lei, carecendo, contudo, de uma outorga ou legitimidade para tanto (GARGARELLA, 1997, p. 57).

Gargarella (1997, p. 70) por fim menciona que as instituições devem possuir abertura suficiente aos cidadãos, pois "os órgãos políticos atravessam uma severa crise que precisa ser atendida, aperfeiçoando as instituições existentes e as abrindo - de um modo como não se encontram hoje - à cidadania".

Assim, se verifica que os argumentos que cercam a questão da legitimidade dos juízes tomarem a decisão, ou, terem a última palavra sobre determinado assunto se reveste no fato de que estes não possuiriam credenciais para passar por cima da vontade dos poderes eleitos. O Poder Judiciário careceria, assim, de uma legitimidade democrática, pois os seus integrantes não são eleitos pelo povo como ocorre no Poder Legislativo e Executivo, bem como podem desconhecer a própria vontade do povo, mesmo quando invocam tais vontades nas suas decisões.

Ainda, alguns autores defendem a ideia de que o controle constitucional deve ser procedimental e não substancial, o que significa dizer que o Poder Judiciário não poderia interferir sobre questões de valores, mas tão somente assegurar uma garantia de um procedimento democrático de deliberação.

Pode-se dizer sucintamente que "para teoria procedimentalista, os valores substantivos de uma sociedade devem ser escolhidos por meio de uma deliberação 
democrática, ou seja, pelos poderes representativos do povo(...)" (BARBOZA, 2007, p. 47).

\subsubsection{Argumentos favoráveis a revisão judicial.}

Como foi verificado, há diversas críticas com relação a possibilidade da revisão judicial, bem como ao fenômeno do constitucionalismo, sendo, inclusive, criticada a supremacia constitucional, porém há autores que defendem a possibilidade de tal supremacia, assim como a possibilidade da revisão judicial dos atos e leis dos demais poderes.

Com relação às críticas acerca de um possível aspecto antidemocrático da Constituição, seja pela ausência de um acordo entre o povo sobre o conteúdo da Constituição, seja pelo fato de que as gerações futuras podem não concordar com o texto constitucional promulgados pelos antigos constituintes, Waluchow (2005) estabelece um contraponto a tal argumento, senão vejamos.

Uma alternativa aos desacordos e problemas democráticos da Constituição ou Carta de Direitos pode ser buscada não por conceitos ambiciosos de uma política moral sólida, mas sim basear no que Waluchow (2005, p. 208) chama de overlapping consensus que em tradução livre pode significar como um consenso sobreposto, mais precisamente normas morais que são mantidas ao longo do tempo pela sociedade, e que possa ser resistida pelo teste de desacordo de alguns.

O contraponto a tal visão é o problema de que esta estabilidade do consenso pode não resistir como consenso no futuro, sendo citado o exemplo da consciência da igualdade racial que se modificou durante o tempo (WALUCHOW, 2005, p. 208).

Mas estas mudanças ocorrem de forma regular, e podem ser representações de concordância e pré-compromissos estáveis, tornando a Carta de Direitos útil a direitos fundamentais coerentes com a forma democrática de governo (WALUCHOW, 2005, p. 208). 
Ainda, em contraponto a própria ideia de uma Constituição fixa que não permite mudanças e que, portanto, em decorrência do tempo pode se tornar antidemocrática, Waluchow (2005) vai além de tal raciocínio da noção da Carta de Direitos como ponto fixo e estável, para conceituá-la como uma mistura de pré-compromisso com a humildade, explicando que não temos todas as respostas para os desafios morais e devemos aceitar isso com humildade, contudo, devemos projetar as instituições políticas e jurídicas de forma a atender as características da situação, ou seja, o texto Constitucional deve ser projetado para atender os futuros anseios do povo e ser permissível ao ingresso de novas necessidades e direitos (WALUCHOW, 2005, p. 222).

A compreensão da importância desta concepção de uma Carta de Direitos afeta não somente o Poder Legislativo na medida que restringe os limites morais da atuação do governo e sua observância enquanto disposta na referida Carta, mas também o papel dos juízes quando da avaliação de uma norma ser inconstitucional ou incongruente com a Carta de Direitos, uma vez que, de modo a evitar impactos extremos, optam por dar interpretação conforme a Carta ou até mesmo deferentes à intenção do legislador em seus atos ao invés de agir de forma arbitrária (WALUCHOW, 2005, p. 208-211).

Quando se faz necessário enfrentar questões fundamentais, especialmente aquelas que envolvem aplicação de direitos constitucionais fundamentais a questões de justiça básica, o apelo a valores morais é inevitável, até porque as normas que estabelecem direitos humanos ou fundamentais são "sempre abertas à complexidade da vida, dependentes das situações de aplicação para ganharem a devida concretude" (CARVALHO, 2007, p. 10). Desse modo, só no caso concreto, o aplicador poderá "reconhecer a norma geral e abstrata do ordenamento, previamente aprovada, capaz de regular aquele caso específico sem resíduos de injustiça." (DWORKIN, 2006, p. 11).

Nessa medida, é possível falar numa moralidade constitucional da comunidade que, para Waluchow (2008), significa "o conjunto de normas morais e juízos ponderados, atribuídos de forma adequada a comunidade como um todo, como representando seus verdadeiros compromissos morais", mas que de alguma forma 
“estejam ligados ao seu direito e práticas constitucionais” (WALUCHOW, 2008, p. 76).3

Em síntese, a moralidade política pressuposta pelas leis e instituições da comunidade (DWORKIN, 2002, p. 197).

Os critérios morais influenciam as decisões judiciais, especialmente quando se interpreta a Constituição, na medida em que esta prevê "instâncias que impõem limites morais a quaisquer leis que possam ser validamente criadas" (DWORKIN, 2006, p. 1011) em determinado país. Do mesmo modo, as restrições impostas pelos direitos fundamentais aos Poderes Públicos constituem restrições morais (DWORKIN, 2006, p. 42).

Seguindo na importância de se ter uma Carta de Direitos ou uma Constituição, Rawls (2003) entende que "existe de fato uma Constituição (não necessariamente escrita) com uma carta de direitos que especifica essas liberdades e é interpretada pelos tribunais como limite constitucional à legislação" (RAWLS, 2003, p. 205).

Outrossim, a Constituição, enquanto Carta de Direitos, não possui somente a função de assegurar os direitos fundamentais, mas também "são aplaudidos pelo valor simbólico que eles são capazes de incorporar" (WALUCHOW, 2005, p. 221), sendo que neste contexto a Constituição pode auxiliar "a definir e reforçar o caráter da nação como publicamente comprometido, nas suas práticas legais e morais, com os direitos e valores fundamentais que inclui”" (WALUCHOW, 2005, p. 221).

\footnotetext{
${ }^{3}$ Nas palavras do autor, a moralidade constitucional da comunidade significa "the set of moral norms and considered judgments, properly attributable to the community as a whole as representing its true moral commitments, but with the following additional property: They are, in some way tied to its constitutional law and practices. Following Dworkin, we might say it is "the political morality presupposed by the laws and institutions of the community". "o conjunto de normas morais e julgamentos considerados, propriamente atribuível à comunidade como um todo como representando seus verdadeiros comprometimentos morais, mas com a seguinte propriedade adicional: Eles estão, de algum modo ligados às suas práticas e leis constitucionais. Seguindo Dworkin, nós poderíamos dizer que é 'a moralidade política pressuposta pelas leis e instituições da comunidade"'. (WALUCHOW, 2008, p. 76).
} 
Com relação ao fato de que a Constituição como fonte suprema, bem como a revisão judicial carecem de um caráter democrático, quando analisado friamente, não se sustenta tal argumentação.

Primeiramente há que se deixar claro qual o conceito de democracia para os autores que são contra a revisão judicial, e neste contexto, se verifica que a democracia para os que sustentam a ausência de caráter democrático do judicial review trata-se de um conceito puramente formal, ou seja, ela "identifica a democracia com base na forma e no procedimento idôneo para garantir que as decisões políticas sejam expressão da vontade geral" (MENEZES NETO; MORAIS, 2013, p. 61), e pode até parecer que tais autores estejam certos, a não ser o fato de que "vigora, nas democracias "puramente formais", a ideia de que a formação de um consenso majoritário seria capaz de legitimar qualquer abuso e rechaçar os sistemas mediadores, limitadores e controladores" (MENEZES NETO; MORAIS, 2013, p. 61).

Uma democracia puramente formal, "embora seja importante, é insuficiente para definir adequadamente o fenômeno democrático moderno e, portanto, para limitar e vincular seu conteúdo" (MENEZES NETO; MORAIS, 2013, p. 61), além de carecer de uma proteção eficaz contra a supressão de direitos de uma minoria, bem como a opressão proposta por uma maioria (FERRAJOLI, 2008, p. 25).

Portanto, a democracia "pode ser caracterizada, especialmente, pelas limitações impostas através das cartas constitucionais ao exercício de todo poder, público ou privado" (MENEZES NETO; MORAIS, 2013, p. 63), sendo que neste conceito, a democracia é chamada de democracia Constitucional, e nesta vertente Menezes Neto e Morais (2013) mencionam que "contrário do que se possa supor, tanto a regra da maioria como a do mercado permanecem válidas na democracia constitucional, mas, em vez de absolutas, restringem-se àquilo que Ferrajoli entende por "esfera do decidível" (MENEZES NETO; MORAIS, 2013, p. 63), pois aqui se retoma o conceito de Ferrajoli já mencionado acerca dos limites do Poder Judiciário quando do exercício da interpretação judicial. 
Em sentido contrário, na medida em que as decisões tomadas através de poderes teoricamente democráticos seriam preferíveis do que a tomada de decisão pelo Poder Judiciário, verifica-se que há legitimidade de o Poder Judiciário controlar os demais poderes se tais decisões "forem fundamentados em princípios constitucionais neutros" (BARBOZA, 2007, p. 57).

De acordo com Dworkin (2001), a legitimidade da tomada de decisão pelo Poder Judiciário no ato de controlar os demais poderes, também decorre da "supremacia dos direitos fundamentais, os quais, segundo ele, dariam legitimidade suficiente à atuação do Poder Judiciário" (BARBOZA, 2007, p. 61), o que leva a conclusão de que o Poder Judiciário estaria autorizado a interferir nas leis ou atos dos demais poderes quando "estiverem em contrariedade àqueles direitos fundamentais" (BARBOZA, 2007, p. 61).

Contudo, para salvaguardar os direitos fundamentais, os julgadores não podem dispor de argumentos eminentemente políticos pela ausência de legitimidade para tanto (DWORKIN, 2001, p. 6), pois os julgamentos de política seriam atribuições exclusivas dos Poderes Legislativo e Executivo [...] e, consequentemente, não poderiam ser objeto de controle ou aplicação pelos tribunais (BARBOZA, 2007, p. 60).

Seguindo na concepção de Dworkin (2001, p. 32) acerca do judicial review, se verifica que tal instrumento pode tutelar os direitos fundamentais, protegendo um grupo minoritário que não possui acesso político, e, portanto, o "judicial review pode conviver com total harmonia com o princípio da democracia" (BARBOZA, 2007, p. 62).

Verifica-se, ainda, que os juristas se deparem com algum caso difícil de tutela de direitos, ainda há como chegar-se a solução do caso, uma vez que "eles recorrem a padrões que não funcionam como regras, mas operam diferentemente, como princípios, políticas e outros tipos de padrões" (DWORKIN, 2001, p. 36).

Se percebe que com a afirmativa de que é permissível o controle de constitucionalidade pelo Poder Judiciário dos atos normativos dos demais poderes, os juízes podem proteger as minorias em detrimento de maiorias, reformando o princípio democrático (DWORKIN, 2001, p. 32). 
Por sua vez, RAWLS também aceita como "possível que os tribunais tenham poderes para limitar ou revisar as leis provindas dos órgãos políticos, desde que seja com o objetivo de proteção dos direitos e liberdades fundamentais" (BARBOZA, 2007, p. 67).

Neste passo, Rawls (2003) menciona que deve ser tirado o poder de dispor do Poder Público quando se trata de algumas garantias necessárias, e para tanto, deve ser fixado "de uma vez por todas os direitos e liberdades básicos e atribuir-lhes especial prioridade" (RAWLS, 2003, p. 162), ou seja, "Rawls apesar de dar importância a uma concepção procedimental de democracia, prioriza a supremacia dos direitos básicos de liberdade e igualdade" (BARBOZA, 2007, p. 68). Relembre-se, ainda, que a democracia puramente formal não se presta a tentar salvaguardar os direitos e garantias fundamentais, podendo a maioria sobrepor suas vontades e suprir os direitos conquistados, devendo, nesta concepção, a sociedade se resguardar através de um núcleo rígido de direitos e garantias fundamentais que não podem ser dispostos através do meio político.

Como visto, tanto a supremacia Constitucional quanto a possibilidade da revisão judicial guardam profundos desacordos na doutrina, há, porém, um terceiro posicionamento, qual seja de Waluchow (2005) acerca da concepção da Constituição como Árvore Viva.

Tal concepção demonstra ser mais moderada sobre a temática e se torna crucial para o que se pretende, vez que se insurge como um possível posicionamento, que adaptado ao sistema brasileiro, poderá servir como matriz teórica e como um contraponto às alegações de poderes em tese ilimitados do Poder Judiciário para rever os atos e leis dos demais poderes, bem como em relação ao posicionamento que ainda se prende ao Estado Legal com a vedação da interpretação pelo magistrado.

\section{UMA NOVA COMPREENSÃO DE CONSTITUIÇÃO? A CONSTITUIÇÃO COMO ÁRVORE VIVA DE WIL WALUCHOW}


Para fixar os limites da revisão judicial, é importante compreender a teoria da Constituição como uma árvore, ou melhor, como uma árvore viva conforme trabalha Waluchow (2005).

Waluchow menciona que diante das críticas no tocante a Constituição e revisão judicial, há que se adotar uma terceira compreensão de Carta de Direitos, não como um ponto fixo e pré-determinado, mas sim como Lord Sankey em Edwards, em um caso constitucional canadense em 1930, decidido pelo Conselho Privado e conhecido como "O Caso das Pessoas", bem como a metáfora "árvore viva" da Constituição, sendo que em tal metáfora os direitos que estão previsto na Carta de Direitos não são pontos fixos de pré-compromissos, mas sim simbolizam que a Carta é uma árvore viva capaz de expandir-se dentro de seus limites. ${ }^{5}$ Ou seja, embora existam pré-compromissos morais, eles seriam flexíveis (WALUCHOW, 2005, p. 215).

Para tal compreensão da necessidade de adoção de uma Carta de Direitos, o autor inicia expondo a sociedade antes e depois da lei, mencionando que há a necessidade de

\footnotetext{
${ }^{4}$ O Caso das Pessoas, ou originalmente "The Person Case" é referência ao caso Edwards v. AG do Canadá decido pelo Comitê Judiciário do Conselho Privado de Londres, Inglaterra. À época, mulheres não poderiam ocupar cargos públicos como, por exemplo, Senadoras, pela interpretação judicial realizada em 1928 pela Suprema Corte do Canadá, pois de acordo com a interpretação restritiva da Lei Britânica da América do Norte (LBAN), mais especificamente na Seção 24 da LBAN, a qualificação como pessoas na referida seção se destinava somente aos homens por interpretação, pois a análise e conclusão deveria ser baseada na LBAN em 1867, quando a Lei foi aprovada e, consequentemente à época mulheres não eram consideradas como "pessoas". Contudo, acionado o Comitê Judiciário do Conselho Privado de Londres, Inglaterra a resolver a controvérsia, ficou sedimentado que as mulheres possuíam o direito de se candidatar e exercer o cargo de Senadora, podendo ser consideradas como "pessoas" para fins do que se dispunha na seção 24 da LBAN. Ademais, foi salientado que "A Lei Britânica da América do Norte plantou no Canadá uma árvore viva capaz de crescer e se expandir dentro de limites naturais. O objetivo da lei era conceder a Constituição ao Canadá” (Edwards v. AG do Canadá, 1930, p. 9).

${ }^{5}$ Seria possível também fazer um paralelo da árvore viva, com as interpretações e reinterpretações a partir de uma sociedade aberta de intérpretes. Ou seja, interpreta-se e reinterpreta-se o passado, que adquire novos significados e contornos. Nessa orientação, os significados dos direitos humanos e fundamentais serão sempre reinterpretados e reescritos de acordo com a dinâmica da sociedade. Ver também Häberle (2002).
} 
uma regra geral, de modo a possibilitar o exercício dos direitos, sendo que tal regra não deverá ser extremamente ampla, mas ao mesmo tempo, poderá ser um indicativo por exemplo, de quem poderá editar uma lei, ou seja, um formalismo da edição de uma lei (WALUCHOW, 2005, p. 215).

Há que se ressaltar que, conforme menciona Waluchow (2005) as regras definidas podem ser aplicadas por particulares sem nova orientação ou ponderação, e, por outro lado, há necessidade de se deixar em aberto a regra, para que as questões sejam enfrentadas de acordo com o caso concreto (WALUCHOW, 2005, p. 217).

Ou seja, o autor menciona que as regras devem ser dirigidas a orientar a aplicação do Direito, não podendo recair no formalismo exagerado, mas não significando que não devam desempenhar papel algum na resolução dos casos (WALUCHOW, 2005, p. 217).

A concepção de Waluchow (2005) acerca de árvore viva decorre justamente da incerteza que se tem de possuir todas as respostas para todas as questões morais e aplicação do Direito, e justamente por tal motivo há necessidade de projetar as instituições políticas e jurídicas através da Carta de Direitos de modo a resolver tais conflitos. Ainda, adotando a linha de pensamento de que ações governamentais e/ou jurídicas podem atentar contra direitos fundamentais, pela incompreensão de seu significado, é ainda mais desejável se ter Carta de Direitos de modo a direcionar as ações (WALUCHOW, 2005, p. 218).

Ainda, é realizado um comparativo do Commom Law e da Carta de Direitos, na qual a Carta dá uma certa orientação, enquanto os tribunais aplicam o common law, ou seja, adaptando ao caso concreto, bem como dando flexibilidade para adaptar os direitos da Carta para cada situação analisada (WALUCHOW, 2005, p. 220).

No mesmo norte, rebatendo as críticas realizadas por Waldron ${ }^{6}$ quando menciona os problemas enfrentados pelos Estados Unidos acerca da discussão do aborto ou pena

\footnotetext{
${ }^{6}$ As obras de WALDRON objetos de análise e crítica por WALUCHOW (2005) se referem a: WALDRON, Jeremy, The Dignity of Legislation, 54 Md. L. Rev. 633, 1995, disponível em:
} 
de morte, Waluchow (2005) frisa que, em que pese a possibilidade de emenda constitucional ser difícil, ela ainda pode ser adotada, e, consequentemente, corrigir alguns direitos ou valores morais adotados na Carta de Direitos. Desta forma, permite corrigir quando o legislador erra na escolha da linguagem a ser adotada, além do que apesar das dificuldades em torno do debate, as questões foram suficientemente enfrentadas pelos Estados Unidos (WALUCHOW, 2005, p. 220).

A resposta para a pergunta realizada por Waldron (2005, p. 221) "Por que não abandonar a Carta de Direitos e adotar um sistema de common law realizado pelos juízes, tribunais, legislaturas e público geral?" é de que seria possível adotar um sistema misto, ou seja, um sistema que permitisse uma flexibilidade própria do common law, mas com certa "fixidez", gerando uma mistura aceitável, bem como é de grande relevância o seu valor simbólico, uma vez que reforçam a noção de uma identidade de nação comprometida com as práticas jurídicas e morais (WALUCHOW, 2005, p. 221).

Não obstante, ressalta Waluchow (2005, p. 224) "a exigência de que os julgamentos sejam publicamente defendidos à luz do princípio constitucional pode, às vezes, funcionar contra quaisquer preconceitos políticos aos quais os juízes possam estar sujeitos".

Com relação a revisão judicial, Waluchow (2005) menciona que Waldron está condenado em sua própria teoria, uma vez que se assemelha a Descartes, quando tudo estava sujeito a dúvidas, não podendo chegar-se a nenhuma conclusão a não ser a própria dúvida. Mais precisamente, aponta que Waldron coloca o critério de desacordo razoável, porém o padrão estabelecido não pode ser cumprido, pairando a dúvida com relação à própria decisão da maioria proposta por Waldron, bem como subestima a potencialidade de tomada de decisões pelos tribunais, não podendo refutar, portanto, a teoria dos defensores da Carta de Direitos com relação ao judicial review (WALUCHOW, 2005).

<http://digitalcommons.law.umaryland.edu/mlr/vol54/iss2/12> e, WALDRON, Jeremy. Law and Disagreement. New York: Oxford University Press, 1999. 
A ideia de Waldron acerca da decisão pela maioria defende que os juízes ou Cortes não são melhores ou possuem senso melhor de tomada de decisão que as demais pessoas, portanto, suas decisões não poderiam se sobrepor a decisão da maioria representativa (legislativo).

Contrariando a suposição acima levantada por Waldron, Waluchow (2005) menciona que nem sempre juízes possuem decisões piores que o legislador, uma vez que não estão sujeitos às mesmas pressões que os legisladores estão (apoio, reeleição, interesses de um grupo especial, interesses partidários), sendo a decisão judicial o caminho mais seguro para proteger direitos de grupos impopulares. Em que pese reconhecer que há diversos fatores que possam influenciar e afastar os juízes de um julgamento imparcial e sem pressão alguma, o autor ainda prefere que as decisões possam ser tomadas pela revisão judicial, ou seja, pelos juízes (WALUCHOW, 2005, p. 225).

Ainda, a respeito da revisão judicial, é ressaltado que esta pode trazer à baila discussões envolvendo toda a população acerca de direitos e moral, fazendo com que a tomada de decisão seja a melhor possível (WALUCHOW, 2005, p. 227).

Por fim, o autor menciona que é desejável ter uma Carta de Direitos, não como ponto fixo de acordo e pré-compromissos, mas sim como árvores vivas, sendo que suas raízes são vivas (por precedentes e os termos utilizados para positivar os compromissos morais da carta), podendo ser desenvolvido (common law) ao longo do tempo pela jurisprudência (WALUCHOW, 2005, p. 227).

Ousa-se, neste ponto, discordar das mencionadas "raízes" da árvore viva, uma vez que acreditamos que a Constituição enquanto árvore viva possui suas raízes firmadas em outro local, ou seja, em outra matéria, sendo que, na verdade, a jurisprudência corresponderia aos galhos das árvores em conjunto com a legislação interna, e as suas folhas poderiam ser simbolizadas pela aplicação dos direitos advindos da raiz, senão vejamos. 


\section{AS RAÍZES DA ÁRVORE COMO SENDO OS DIREITOS HUMANOS E A CONSTITUIÇÃO DA REPÚBLICA}

Para Waluchow (2005), as raízes da Constituição como árvore viva seriam os precedentes e os termos utilizados para positivar os compromissos morais da carta, sendo que a Constituição ou Carta de Direitos é simbolizada pela árvore, apesar de aceitar a ideia de Waluchow, o presente artigo ousa discordar em alguns pontos, senão vejamos.

A construção de Waluchow (2005) sobre a Constituição como Árvore viva foi projetada para o sistema do Common Law, e assim o sendo, é impossível a importação de qualquer teoria, sem, contudo, realizar adaptações, e por tais motivos a teoria elaborada por Waluchow deve sofrer pequenas mudanças para servir ao sistema jurídico brasileiro, uma vez que em essência, o Brasil é baseado no Civil Law.

Assim, o que se pretende construir neste ponto, se refere que a árvore, em verdade, é a própria democracia, sendo que suas raízes são a Constituição enquanto guardiã dos direitos e garantias fundamentais, bem como os Direitos Humanos.

Neste tear, antes mesmo de se estabelecer os motivos pelos quais se deve acreditar que as raízes que sustentam a Constituição como árvore viva são os Direitos Humanos, deve-se citar o que se compreende por tais direitos.

Em um primeiro momento, Direitos Humanos pode significar conforme Hesse citado por Ramos (2001, p. 27), como "um conjunto mínimo de direitos necessários para assegurar uma vida do ser humano baseada na liberdade e na dignidade".

No que tange a conceituação dos direitos fundamentais da pessoa humana, podese dizer que tais direitos estão fundados principalmente em dois pilares, a liberdade e a dignidade e que, por tais motivos, os direitos fundamentais da pessoa humana não são exaustivos, podendo ser acrescidos com novos direitos fundamentais, de modo que tais direitos fazem com que o sujeito consiga exercer e participar plenamente da vida, sendo, inclusive, um conceito fluído e aberto. 
A ideia de conquista de Direitos Humanos advém das diversas transformações e inserções em seu rol durante a história, passando pelos conceitos de direitos fundamentais da pessoa humana, no direito natural, da razão iluminista, passando pelos Direitos Humanos fundamentais sociais, teoria liberal-social, bem como a concepção de classificação de Direitos Humanos em gerações (RAMOS, 2001, p. 27-32).

A conquista de direitos também se confunde com a própria noção de democracia, uma vez que de acordo com Silva (2014, p. 125) a democracia é "conceito histórico. Não sendo por si um valor-fim, mas meio e instrumento de realização de valores essenciais de convivência humana, que se traduzem basicamente nos direitos fundamentais do homem [...]", e mais, Silva (2014, p. 126) ainda menciona que "a democracia não é um mero conceito político abstrato e estático, mas é um processo de afirmação do povo e de garantia de direitos fundamentais que o povo vai conquistando no correr da história", sendo que Piovesan (2013, p. 373) segue no mesmo sentido quando afirma que "a afirmação dos Direitos Humanos como tema global vem ainda acenar para a relação de interdependência existente entre democracia, desenvolvimento e Direitos Humanos".

Com a internacionalização dos Direitos Humanos através das Ligas das Nações acelerado pelo fim da Guerra Fria e após a $2^{\text {a }}$ Guerra Mundial, tornou-se tema de importância global. Assim, nos dias atuais, são considerados Direitos Humanos todos os direitos determinados como fundamentais da pessoa humana nas convenções internacionais, bem como por normas não-convencionais (RAMOS, 2001, p. 46).

No Brasil, a Constituição da República de 1988 trouxe em seu texto legal direitos sociais passando a ser considerados direitos fundamentais, porém não é um rol exaustivo e restritivo, uma vez que "trouxe um conceito materialmente aberto de direitos fundamentais, de modo que é possível a inclusão de direitos não previstos no rol do art. 5, como é o caso dos direitos sociais" (BÜHRING, 2015, p. 56).

E mais, através da leitura do artigo $5^{\mathrm{a}}, \S 2^{\circ}$ da Constituição da República, nota-se que houve a preocupação do legislador abrir margem a promoção dos direitos e garantias 
fundamentais decorrentes dos pactos e tratados internacionais, uma vez que dispõe que os direitos e garantias previstas no artigo $5^{\circ}$ não excluem os decorrentes de pactos e tratados internacionais celebrados pelo Brasil, o que significa dizer que deixou em aberto a possibilidade de avanço em matéria de direitos e garantias.

Assim, houve a preocupação de assegurar as garantias dos pactos e tratados internacionais no ordenamento jurídico interno brasileiro, mais especificadamente nas garantias fundamentais da Constituição da República, deixando assim, aberta a cláusula à novas garantias supervenientes a Carta.

Adotando este posicionamento, se verifica que a partir da consagração de direitos fundamentais no corpo do texto constitucional, a Constituição pode ser compreendida como "a ordenação sistemática e racional da comunidade política através de um documento escrito no qual se declaram as liberdades e os direitos e se fixam os limites do poder político" (CANOTILHO, 2002, p. 52), não se limitando, contudo, ao texto estrito da lei, podendo haver ampliação de direitos e garantias fundamentais no decorrer do tempo.

Neste mesmo contexto, retomando o que foi dito no primeiro tópico, a adoção de uma Constituição rígida por parte dos Estados, com a promoção de direitos fundamentais, também faz parte do contexto da virada do Estado Legal para o Estado Constitucional, sendo que ambos derivam dos temores vivenciados pela guerra, bem como para a adoção de um sistema de freios aos abusos autoritários. O que não significa que já não existisse a preocupação ou existência dos Direitos Humanos ou até mesmo de Constituições, mas o que se quer dizer é que a partir da $2^{\mathrm{a}}$ Guerra Mundial houve uma maior preocupação em âmbito internacional na proteção da sociedade contra os abusos.

Em um aspecto interamericano, a origem da promoção dos Direitos Humanos ocorre "quando foi realizada a 9 a Conferência Interamericana entre os Estados da região. Nessa conferência, aprovou-se a Declaração Americana de Direitos e Deveres do Homem e a Carta da Organização dos Estado Americanos (OEA)" (RAMOS, 2006, p. 
56). A universalidade dos Direitos Humanos foi reconhecida pela Declaração Americana de Direitos, sendo que os direitos essenciais ao homem estavam ligados a "sua condição humana" (RAMOS, 2006, p. 56-57).

Sendo os Direitos Humanos considerados conquistas históricas pela humanidade conforme afirmado anteriormente, Piovesan (2000) menciona que os direitos sociais "são direitos intangíveis e irredutíveis, que são providos da garantia da suprema rigidez, o que torna inconstitucional qualquer ato que tenda a restringi-los ou aboli-los" (PIOVESAN, 2000).

Noutro lado, além do texto legal, há que ser considerado os princípios constitucionais, e neste contexto de proibição ao retrocesso, bem como a promoção de direitos encontra respaldo na própria regra de interpretação conforme menciona Bühring (2015) quando menciona Alexy: “os princípios são mandados de otimização, cabe, portanto, interpretação de acordo com o caso concreto, enquanto as regras vêm previamente definidas (no texto constitucional) e não cabe qualquer interpretação" (BÜHRING, 2015, p. 58).

Nesta mesma direção de proibição ao retrocesso, segue a Convenção Americana de Direitos Humanos, que em seu artigo 29 assim estabelece:

Artigo 29. Normas de interpretação

Nenhuma disposição desta Convenção pode ser interpretada no sentido de: a. permitir a qualquer dos Estados Partes, grupo ou pessoa, suprimir o gozo e exercício dos direitos e liberdades reconhecidos na Convenção ou limitá-los em maior medida do que a nela prevista;

b. limitar o gozo e exercício de qualquer direito ou liberdade que possam ser reconhecidos de acordo com as leis de qualquer dos Estados Partes ou de acordo com outra convenção em que seja parte um dos referidos Estados; c. excluir outros direitos e garantias que são inerentes ao ser humano ou que decorrem da forma democrática representativa de governo; e

d. excluir ou limitar o efeito que possam produzir a Declaração Americana dos Direitos e Deveres do Homem e outros atos internacionais da mesma natureza. (CONVENÇÃO AMERICANA DE DIREITOS HUMANOS, 1969). 
E mais, o Art. $5^{\circ}, \S 2^{\circ}$ do Pacto Internacional dos Direitos Econômicos, Sociais e Culturais (1966), determina que:

\begin{abstract}
Não se admitirá qualquer restrição ou suspensão dos Direitos Humanos fundamentais reconhecidos ou vigentes em qualquer país em virtude de leis, convenções, regulamentos ou costumes, sob o pretexto de que o presente Pacto não os reconheça ou os reconheça em menor grau.
\end{abstract}

No mesmo sentido, o art. $5^{\circ}$, do Pacto Internacional dos Direitos Civis e Políticos (1966) também veda o retrocesso de direitos conquistados:

Não se admitirá qualquer restrição ou suspensão dos Direitos Humanos fundamentais reconhecidos ou vigentes em qualquer Estado-parte no presente Pacto em virtude de leis, convenções, regulamentos ou costumes, sob pretexto de que o presente Pacto não os reconheça ou nos reconheça em menos grau.

Posto dessa forma, é inevitável que haja a interpretação das leis e atos normativos pelo Poder Judiciário após a virada do Estado Legal para o Estado Constitucional de Direito, vez que sequer haveria sentido um controle de constitucionalidade de leis ou atos exercidos pelo próprio poder que derivou o ato ou lei, pois o contrário significaria um atentado a própria noção de democracia adotada no presente artigo que se filia a noção de democracia de Silva (2014, p. 126): “a democracia não é um mero conceito político abstrato e estático, mas é um processo de afirmação do povo e de garantia de direitos fundamentais que o povo vai conquistando no correr da história".

$\mathrm{Ou}$ seja, a possibilidade de conquistas e adições de direitos e garantias fundamentais só tende a fortalecer a própria democracia, seja pela via judicial, seja pelos demais poderes, não dispensando, contudo, a possibilidade de diálogo entre os poderes.

A noção de democracia representativa histórica sustentada pelos autores contra a revisão judicial perdem força ao mesmo tempo em que se abre espaço para as novas necessidades das gerações futuras, sendo restringido tão somente o retrocesso em matéria de Direitos Humanos e direitos fundamentais, que compõe um núcleo rígido por 
se tratarem de conquistas da própria humanidade, ou seja, um conteúdo mínimo de direitos e garantias fundamentais capaz de dar sustentação a própria democracia.

Desta forma, ao menos no Brasil, as raízes da Árvore Viva não são interpretações judiciais ou precedentes judiciais, mas sim a própria Constituição da República e os Direitos Humanos, vez que todo o ordenamento jurídico, bem como as próprias interpretações dadas pela jurisprudência são decorrentes da leitura desta e não ao contrário. De qualquer modo, é importante esclarecer que o constitucionalismo do common law aceita a ideia da existência de uma Constituição não escrita ao lado da Constituição escrita. Inclusive a Suprema Corte do Canadá estabeleceu que a Constituição canadense é primordialmente escrita, mas que por trás das palavras escritas existem pressupostos vitais não declarados nos quais o texto se fundamenta e, portanto, há uma série de princípios constitucionais não escritos aos quais os juízes podem dar força normativa. ${ }^{7}$

Waluchow também defende que as Constituições contêm mais do que apenas o

\footnotetext{
7 "Quais são aqueles princípios basilares? Nossa Constituição é primordialmente escrita, produto de 131 anos de evolução. Por trás da palavra escrita há uma linhagem histórica que se propaga pelos anos, e que ajuda na consideração dos princípios constitucionais basilares. Estes princípios informam e sustentam o texto constitucional: eles são as premissas não proferidas e vitais nas quais o texto se baseia. A discussão a seguir traz quatro princípios constitucionais fundamentais da maior relevância para a resolução desta Referência: o federalismo, a democracia, o constitutionalismo e a rule of law, e o respeito pelos direitos de minoria. Estes princípios definidores funcionam em simbiose. Nem um deles pode ser definido isoladamente do outro, nem qualquer deles supera ou exclui a eficácia do outro. [...] Princípios constitucionais fundamentais podem em certas circunstâncias dar origem a obrigações legais substantivas (ter "total força legal", como nós descrevemos no Patriation Reference, supra, at p. 845), que constitui limitações substantivas contra a ação governamental. Estes princípios podem originar obrigações muito abstratas e genéricas, ou eles podem ser mais específicos e precisos em sua natureza. Os princípios não são meramente descritivos, mas são também investidos de uma força normativa poderosa, e vinculam tanto as Cortes como os governos. "Em outras palavras", como esta Corte confirmou no Manitoba Language Rights Reference, supra, at p. 752, "no processo de decisão constitutional, a Corte pode considerar postulados não escritos que formam o próprio sustentáculo da Constituição do Canada". É para essa discussão sobre os princípios constitucionais basilares que agora nos voltamos."Essa fundamentação se deu para justificar o princípio federalista, que apesar de não estar na Constituição escrita, faz parte da história e da formação do Canadá, assim, apesar de implícito, é considerado fundamental no sistema constitucional canadense. Por fim, decidiu pela não possibilidade de secessão do Estado do Québec, desse modo, mesmo que houvesse manifestação da maior parte de sua população, eventual secessão só poderia acontecer se houvesse emenda à Constituição. (REFERENCE RE SECESSION OF QUEBEC, 1998).
} 
direito constitucional. Para o autor, essa visão está associada com a de Dicey (1996), que propôs que, além das leis constitucionais, os sistemas de governo limitados constitucionalmente podem conter um número de "convenções constitucionais" (constitutional conventions), que, informalmente, derivam "das práticas da comunidade política e que muitas vezes impõe limites importantes sobre os poderes administrativos básicos estabelecidos pela lei constitucional". ${ }^{8}$

Como visto acima, muitas das constituições contêm muito mais do que direito, do que normas, e certamente muito mais do que normas e direito escrito. Elas contêm, segundo Waluchow (2007, p.47), convenções constitucionais, que, apesar de não terem uma coercibilidade jurídica, podem ser tão importantes para o funcionamento da sociedade política quanto o direito constitucional. O mais importante é que qualquer ato ou lei pode ser considerado inconstitucional por violar uma destas convenções, uma norma constitucional baseada no consenso da sociedade que, sem ser escrita, impõe limites ao exercício do Poder Legislativo.

\section{CONCLUSÃO}

Com o fenômeno do Constitucionalismo, mais precisamente marcado pela virada do Estado Legal para o Estado Constitucional, é inegável que se abriu a oportunidade para o Poder Judiciário interpretar as leis, tendo a Constituição como base.

Por mais que severas críticas possam recair sobre a questão democrática da Constituição, ou da dificuldade de novas gerações estarem sujeitas as vontades dos

\footnotetext{
${ }^{8}$ Waluchow (2007, p. 28-29). Ao enfrentar essa questão, a Suprema Corte do Canadá "utilizou a distinção de Dicey entre lei constitucional e convenção constitucional, regulamentando que (a) não se pressupunha aquiescência provincial para uma matéria de lei constitucional; (b) mas se pressupunha quando se tratava de uma matéria de convenção constitucional - ou seja, existia uma convenção informal entre os vários poderes do sistema político canadense que pressupunham aquiescência provincial para qualquer ação do governo federal que surtia efeito sobre poderes provinciais; e (c) em alguns casos este incluído - convenções constitucionais são pelo menos tão importantes quanto, se não mais importantes, que as leis constitucionais. [...]".
} 
antepassados expressas na Constituição, foi fixado durante o percorrer do presente artigo um ponto que mostra uma Constituição permissiva em avanços com relação às vontades e conquistas humanas, deixando de lado a ideia de que a Constituição é um ponto fixo, intransponível e impossível modificação, o que poderia até então legitimar as críticas lançadas pelo posicionamento contrário, tanto com relação da Constituição como norma fundante do Estado Constitucional de Direito, quanto a possibilidade de revisão judicial.

Ao que se verifica, a Constituição brasileira não é dotada de fixidez extrema e imutável, sua cláusula de abertura abre espaço para a inclusão de direitos humanos decorrentes ou implícitos de seu texto, sendo, permitido, inclusive, a possibilidade de interpretação das normas conforme o avanço da própria sociedade.

As críticas lançadas com relação ao não atendimento das vontades populares através das decisões judiciais são válidas, desde a perspectiva de uma minoria em que não tenha seus interesses atendidos ou de um certo elitismo na tomada de decisão, porém tais argumentos perdem força quando levada em conta a concepção de uma democracia como árvore viva, cujos direitos conquistados ao longo do tempo tendem a ser ampliados, pois se os direitos são conquistas durante a história, estes são compreendidos como normas que não permitem o retrocesso, assegurando, portanto, os direitos das minorias em eventuais conflitos contra as maiorias.

Outrossim, tais críticas não podem ser formuladas tão somente ao Poder Judiciário, sendo que tanto o Executivo quanto o Legislativo, também podem padecer dos mesmos defeitos. Por tal motivo que se assegura a interação entre os poderes, e, principalmente o poder da revisão judicial, vez que estando adstrito aos princípios constitucionais e comprometido com os Direitos Humanos, deve ainda, racionalizar e justificar as decisões, sendo mais perceptível qualquer abuso na tomada de decisão, o que não se verifica nos órgãos representativos, vez que não há, ou não é necessária, uma justificação da tomada de decisões por parte dos Poderes Legislativo e Executivo.

Ademais, discorda-se dos argumentos de que os juízes ao interpretar a lei receberiam poderes ilimitados ou de que teriam discricionariedade para contrariar os 
direitos conquistados, uma vez que devem encontrar nos Direitos Humanos e fundamentais conquistados durante a história os limites de sua atuação, sendo vedado o seu retrocesso.

Se percebe neste ponto, que o Estado tem a obrigação da proteção e promoção dos Direitos Humanos seja por qual via for (Judiciário, Executivo ou Legislativo). Assim, se o argumento dos que se posicionam contra a possibilidade de revisão judicial for resguardar a democracia, vedar a interpretação que fornece um avanço na conquista de direitos aos cidadãos ou intepretação de incompatibilidade ou inconstitucionalidade de lei que implique em retrocesso de Direitos Humanos, significa ao mesmo tempo, violação da própria noção de democracia que em tese é defendida pelos que se posicionam contra a revisão judicial.

Conforme visto, a Constituição brasileira deixou em aberto a possibilidade para inserir novos direitos e garantias fundamentais, ou seja, permitindo que a "árvore" se adapte às transformações e interpretações em decorrência do tempo e, por tal motivo, não há como se falar em uma ausência de representatividade das gerações futuras, vez que a Constituição não resta imutável, mas com um núcleo rígido (raízes), como sendo os direitos e garantias decorrentes da Constituição da República e Direitos Humanos.

É correta a afirmativa de que a revisão judicial não pode ser uma medida desenfreada e aplicada conforme a própria consciência do julgador, mas que deve obedecer as diretrizes firmadas pela Constituição, bem como pelo Direito Internacional dos Direitos Humanos, e qualquer interpretação que culmine em uma redução de direitos, está fadada a ilegalidade, inconstitucionalidade ou ilegitimidade.

Percebe-se, inclusive, que conforme já mencionado, Dworkin considera válida a interferência do judiciário pautada em princípios e garantias constitucionais, sendo que qualquer decisão que não possua em sua fundamentação em princípios, está fadada a ser considerada ilegítima.

Neste prisma o artigo se baseia na teoria de Waluchow, com pequenas mudanças, sendo que a própria democracia é simbolizada por uma árvore, sendo suas raízes a 
Constituição da República e os Direitos Humanos, e todo e qualquer "galho" (revisão judicial ou atuação do legislativo ou executivo) que cresça será decorrente das próprias raízes do ordenamento, sendo as folhas e frutos o significado da promoção dos Direitos Humanos e implantação dos direitos decorrentes das raízes. Perceba ainda, que podar as raízes (retrocesso em direitos), culminará na morte desta árvore (democracia), sendo que, com a conquista de mais direitos e garantias fundamentais, bem como com o avanço em Direitos Humanos, só tende a dar mais sustentação à própria democracia, aqui simbolizada pela árvore, vez que quanto maiores forem as raízes de uma árvore, menos chances tem ela de sucumbir.

Por outro lado, a partir do momento em que o corpo da árvore possui uma riqueza de nutrientes advinda de suas raízes, dificilmente os seus galhos, folhas e frutos serão considerados ruins ou perecerão, sendo que os galhos tenderão a buscar mais luz para trazer ainda mais nutrientes ao corpo da árvore, porém o inverso também se mostra verdadeiro, vez que uma raiz fraca leva a árvore como um todo a sucumbir.

Por fim, o que se defende no presente artigo é que, com uma base sólida de direitos e garantias fundamentais, dificilmente a estrutura democrática ruirá, sendo que a revisão judicial irá servir justamente para implementação e avanços de novos direitos e garantias fundamentais, levando todo o sistema à prosperidade.

\section{REFERÊNCIAS}

BARBOZA, Estefânia Maria de Queiroz. Jurisdição Constitucional: entre constitucionalismo e democracia. Belo Horizonte: Fórum, 2007.

BRASIL. Constituição da República Federativa do Brasil. 1988.

BRASIL. Supremo Tribunal Federal. ARE-639337. Relator: Min. Celso de Mello. Julgado em 21/06/2011. Publicado em 29/06/2011. 
BÜHRING, Marcia Andrea. Direito Social: proibição de retrocesso e dever de progressão. Revista Direito \& Justiça, Porto Alegre, v. 41, n. 1, pp. 56-73, jan.-jun. 2015 .

CANOTILHO, José Joaquim Gomes. Direito Constitucional e Teoria da Constituição. 6. ed. Coimbra: Almedina, 2002.

CARVALHO NETTO, Menelick de. Entrevista por CARVALHO, Jacqueline Grosse Fernandes. Revista do Tribunal de Contas de Minas Gerais, Belo Horizonte, v. 65, n. 4, p. 10, out./dez. 2007.

CINTRA, Antonio Carlos de Araújo; GRINOVER, Ada Pellegrini; DINAMARCO, Cândido Rangel. Teoria Geral do Processo. 31. ed. São Paulo: Malheiros. 2015.

CONVENÇÃO AMERICANA DE DIREITOS HUMANOS. Pacto San José Da Costa Rica. Disponível em: https://www.cidh.oas.org/basicos/portugues/c.convencao_americana.htm. Acesso em: 06 set. 2018.

DICEY, Albert Venn. An Introduction to the Study of the Law of the Constitution. 8. ed. [S. 1.] Macmillan, 1996.

DWORKIN, Ronald. Uma Questão de Princípio. Trad. Luís Carlos Borges. São Paulo: Martins Fontes. 2001.

DWORKIN, Ronald. A Justiça de Toga. São Paulo: Martins Fontes, 2006.

DWORKIN, Ronald. Levando os direitos a sério. São Paulo: Martins Fontes, 2002.

FERRAJOLI, Luigi. O estado de direito entre o passado e o futuro. In: COSTA, Pietro; ZOLO, Danilo (Orgs.). O estado de direito: história, teoria, crítica. São Paulo: Martins Fontes, pp. 417-464, 2006.

FERRAJOLI, Luigi. Democracia y garantismo. Trad. Perfecto Andrés Ibáñez et al. Madrid: Trotta, 2008.

FIORAVANTI, Maurizio. Estado y constitución. In: FIORAVANTI, M. (Org.). El Estado Moderno en Europa: Instituciones y derecho. Madrid: Editoral Trotta, pp. 1343, 2004. 
GARGARELLA, Roberto. La dificuldade de defender el control judicial de las leyes. Isonomía, Buenos Aires, n. 6, abr. 1997.

GODOY, Miguel Gualano. Devolver a Constituição ao Povo: Crítica à supremacia judicial e diálogos institucionais. Belo Horizonte: Fórum. 2017.

HÄBERLE, Peter. Hermenêutica Constitucional. A sociedade aberta dos intérpretes da Constituição: Contribuição para a interpretação pluralista e procedimental da Constituição.

HIRSCHL, Ran. O novo constitucionalismo e a judicialização da política pura no mundo. Trad. Diego Werneck Arguelhes e Pedro Jimenez Cantisano. Revista de Direito Administrativo, n. 251, pp. 139-178, maio/ago. 2009. Disponível em: bibliotecadigital.fgv.br/ojs/index.php/rda/article/download/7533/6027. Acesso em: 28 ago. 2018.

HIRSCHL, Ran. The political origins of the new constitutionalism. Disponível em: http://www.repository.law.indiana.edu/cgi/viewcontent.cgi?article=1276\&context=ijgl s. Acesso em: 27 ago. 2018.

LAMY, Eduardo de Avelar. Considerações sobre a Influência dos Valores e Direitos Fundamentais no Âmbito da Teoria Processual. Revista Sequiência (Florianópolis), n. 69, pp. 301-326, dez. 2014.

LEVINSON, Sanford. Our Undemocratic Constitution: Where the Constitution Goes Wrong. New York: Oxford University Press. 2006.

MARINONI, Luiz Guilherme. Curso de Processo Civil: Teoria Geral do Processo, São Paulo: Revista dos Tribunais, 2015.

MENEZES NETO, Elias Jacob de; MORAIS, Jose Luis Bolzan de. A crise do Estado e a perspectiva de Luigi Ferrajoli sobre a crise da democracia constitucional. Revista do Instituto de Hermenêutica Jurídica - RIHJ, Belo Horizonte, ano 11, n. 14, pp. 5982, jul./dez. 2013.

PACTO INTERNACIONAL DOS DIREITOS CIVIS E POLÍTICOS. 1966. Disponível em: http://www.planalto.gov.br/ccivil_03/decreto/1990-1994/d0592.htm. Acesso em: 06 set. 2018.

PACTO INTERNACIONAL SOBRE DIREITOS ECONÔMICOS, SOCIAIS E CULTURAIS. 1966 . em: 
http://www.planalto.gov.br/ccivil_03/decreto/1990-1994/d0591.htm. Acesso em: 06 set. 2018.

PIOVESAN, Flávia. Direitos Humanos e o Direito Constitucional Internacional. 14. ed. rev. e at. São Paulo: Saraiva. 2013.

PIOVESAN, Flávia. Não à Desconstitucionalização dos Direitos Sociais. CONJUR. 02/06/2000. Disponível em: https://www.conjur.com.br/2000-jun02/conquistas_trabalhistas_preservadas. Acesso em: 06 jul. 2020.

RAMOS, André de Carvalho. Direitos Humanos em Juízo: Comentários aos casos contenciosos e consultivos da Corte Interamericana de Direitos Humanos. São Paulo: Max Limonad, 2001.

RAWLS, John. Justiça como Equidade: Uma reformulação. Trad. Claudia Berliner. São Paulo: Martins Fontes. 2003.

REFERENCE RE SECESSION OF QUEBEC. 2 S.C.R. 217, 1998. Disponível em: https://scc-csc.lexum.com/scc-csc/scc-csc/en/item/1643/index.do. Acesso em: 20 maio 2020.

SILVA, José Afonso da. Curso de Direito Constitucional Positivo. 33. ed. rev. e atua. São Paulo: Malheiros.

VANBERG, Georg. The Politics of Constitucional Review. Cambridge University Press, 2004.

WALUCHOW, Wil. Constitutions as Living Trees: An Idiot Defends. Canadian Journal of Law and Jurisprudence, v. 18, n. 2, pp. 207-247, jul. 2005.

WALUCHOW, Wil. Constitutional Morality and Bills of Rights. In: HUSCROFT, Grant (Ed.) Expounding the Constitution: Essays in Constitutional Theory. New York: Cambridge University Press, 2008.

WALUCHOW, Wil. A common law theory of judicial review: the living tree. New York: Cambridge University Press, 2007.

WALDRON, Jeremy. Contra el gobierno de los jueces. Buenos Aires: Siglo XXI, 2018. 
A CONSTITUIÇÃO COMO ÁRVORE VIVA DE WIL WALUCHOW: POR UMA NOVA CONCEPÇÃO DE CORPO E DE SUAS RAÍZES

WALDRON, Jeremy. The Core Against Judicial Review. The Yale Law Journal, 2006

Data da submissão: 05/11/2019

Data da primeira avaliação:14/04/2020

Data da segunda avaliação:20/04/2020

Data da aprovação: 20/04/2020 